\title{
Pseudoephedrine-induced Hemorrhage Associated with a Cerebral Vascular Malformation
}

\author{
Steven K. Baker, Jamie E. Silva, Ken K.S. Lam
}

\begin{abstract}
Background: Sympathomimetic-related intracerebral hemorrhage is well-documented. Most cases are associated with phenylpropanolamine use. Case Report: We report a case of intracerebral hemorrhage occurring in a middle-aged man who suffered from chronic sinusitis and had been ingesting pseudoephedrine daily for one year. This patient was previously well with no known cardiovascular risk factors. Clinical examination revealed no evidence of vasculitis nor coagulopathy and initial neuroimaging (i.e., computed tomography, angiography, magnetic resonance imaging) demonstrated no features consistent with aneurysm, arteriovenous malformation (AVM), cavernoma, nor cerebral metastases. A follow-up cerebral angiogram demonstrated a small AVM arising off a branch of the pericallosal artery and a small arteriovenous fistula arising off the costal marginal branch. The AVM was embolized without incident, however, the AVF was not accessible. Conclusions: Sympathomimetics have long been associated with intracerebral hemorrhage. Since 1979, over 30 published case reports have documented the relationship between phenylpropanolamine and stroke. Only one report links phenylpropanolamine consumption to an intracerebral hemorrhage in a patient with an AVM. There is a paucity of literature etiologically inculpating other ephedra alkaloids in the causation of intracerebral hemorrhage. This is a case of pseudoephedrine-induced intracerebral hemorrhage in a patient with an underlying vascular malformation.
\end{abstract}

RÉSUMÉ: Hémorragie induite par la pseudoéphédrine au niveau d'une malformation vasculaire cérébrale Introduction: L'hémorragie intracérébrale (HIC) en relation avec les substances sympathomimétiques est bien connue. La plupart des cas sont associés à la phénylpropanolamine. Cas clinique: Il s'agit d'un cas de HIC chez un homme d'âge moyen atteint de sinusite chronique qui faisait usage de pseudoéphédrine quotidiennement depuis un an. Ce patient était en bonne santé, sans facteur de risque cardiovasculaire connu. L'examen clinique n'a montré aucun signe de vasculite ou de coagulopathie. À la neuroimagerie (CT, angiographie, RMN), aucune image compatible avec un anévrisme, une malformation artérioveineuse (MAV), un angiome caverneux ou des métastases cérébrales n'a été décelée. Au cours du suivi, une angiographie cérébrale a montré la présence d'une petite MAV issue d'une branche de l'artère péricalleuse ainsi qu'une petite fistule artérioveineuse (FAV) issue d'une branche de l'artère callosomarginale. La MAV a été traitée par embolisation sans incident. Cependant, la FAV n'était pas accessible. Conclusions: Le lien entre les agents sympathomimétiques et l'hémorragie intracérébrale est bien connu. Depuis 1979, plus de 30 cas où il existait une relation entre la phénylpropanolamine et l'accident vasculaire cérébral ont été publiés. On a fait un lien dans un seul cas entre l'utilisation de phénylpropanolamine et l'hémorragie intracérébrale chez un patient ayant une MAV. Il existe peu de publications établissant un lien étiologique entre l'hémorragie intracérébrale et d'autres alcaloïdes de l'éphédra. Ce cas est donc le premier cas d'hémorragie intracérébrale induite par la pseudoéphédrine chez un patient porteur d'une malformation vasculaire.

Can. J. Neurol. Sci. 2005; 32: 248-252

Sympathomimetics (i.e., phenylpropanolamine (PPA), phenylephrine, ephedrine, and pseudoephedrine) found in overthe-counter decongestant and anorectic medications have been implicated in the causation of ischemic and hemorrhagic stroke. Particular interest has focussed on the increased risk of intracerebral hemorrhage ( $\mathrm{ICH}$ ) attributable to PPA ingestion. Since 1979, more than 30 published reports have linked PPA use
From the Department of Medicine (Neurology \& Rehabilitation), McMaster University Medical Center (SKB); Department of Neurology, Hamilton General Hospital (JES);

Department of Physical Medicine and Rehabilitation, Chedoke Hospital; (KKSL); McMaster University, Hamilton, Ontario, Canada.

Received August 4, 2004. AcCePted in FinAl Form DeCEMber 6, 2004

Reprint requests to: S.K. Baker, Department of Medicine (Neurology \& Rehabilitation, Rm 4U4), McMaster University, Hamilton, Ontario, L8N 3 Z5 Canada. 
to $\mathrm{ICH}^{1-16}$ Recently, the Hemorrhagic Stroke Project, an elaborate case-control study, ${ }^{17}$ concluded that PPA exposure from appetite suppressants, and to a lesser extent oral decongestants, significantly increased the risk for hemorrhagic stroke. The adjusted odds ratios (ORa) for the risk of $\mathrm{ICH}$ in women taking diet preparations or cough and cold remedies containing PPA was 16.58 and 1.54 , respectively. Men demonstrated no increased risk for hemorrhagic stroke during chronic PPA use. However, first use of PPA containing products was associated with a commensurate elevated risk for both sexes (ORa for men, 2.95; ORa for women, 3.13). These findings led both the United States Food and Drug Administration (US FDA) and Health Canada to withdraw all products containing PPA from the market.

While this FDA ban represents an important stride to limit over-the-counter availability of catacholaminergics it may be inadequate as other ephedra alkaloids have also been linked to cerebrovascular adverse events. ${ }^{18-20}$ Ephedrine is commonly available in ergogenic dietary supplements and appears to be the predominant form in various preparations inculpated in central nervous system bleeds. There is a paucity of information regarding the independent role of pseudoephedrine as a potential etiologic agent in stroke. In a case-series of four patients, pseudoephedrine use has been associated with gastrointestinal hemorrhage. ${ }^{21}$ We report a case of pseudoephedrine ingestion which was temporally coupled to an ICH in a healthy 50 -yearold man with a latent cerebral arteriovenous malformation.

\section{Case Report}

A healthy 50-year-old right-hand dominant man suffered from chronic sinus congestion for which he took Flonase ${ }^{\mathrm{TM}}$ and Night-time Tylenol Sinus ${ }^{\mathrm{TM}}$ (one capsule nightly for one year). One morning he awoke at approximately 8:00 am feeling quite congested and therefore took an additional dose of his decongestant. He retired back to bed and re-awoke 1.5 hours later experiencing right-sided hemiplegia and a Broca-type aphasia. In the emergency department, his blood pressure was $150 / 103 \mathrm{mmHg}$. An initial computed tomogram scan demonstrated a large $(2 \times 4 \mathrm{~cm})$ left frontoparietal centrum semiovale hemorrhage with slight mass effect (Figure 1). Conservative treatment was chosen after the cerebral angiogram failed to reveal evidence of arteriovenous malformation (AVM) or aneurysm (Figure 3). An MRI was ordered to exclude etiologies such as cavernoma or metastatic disease (Figure 2). These were not found. A screening thoracoabdominal CT was also negative. Flow cytometry demonstrated CD55 and CD59 positive cells ruling out paroxysmal nocturnal hemoglobinuria. The patient developed a deep venous thrombosis in the right popliteal vein and a non lifethreatening acute pulmonary embolism for which an inferior venacaval filter was inserted. A popliteal venogram demonstrated near occlusive thrombus extending from the popliteal vein through to the inferior venacaval filter with involvement of the left common iliac vein. A hypercoaguability workup, including activated protein $\mathrm{C}$ resistance, was unremarkable. He was started on heparin and converted to warfarin, targeting his international normalized ratio between 2.0 and 3.0, with no bleeding complications.

A repeat cerebral angiogram was conducted, eight weeks later, anticipating partial resolution of the edema and hematoma mass effect (Figure 3). This investigation revealed a small vertex AVM arising from a distal (superior internal parietal) branch of the left pericallosal artery. Superselective catheterization confirmed the presence of a small AVM nidus which was embolized with glue. A small arteriovenous fistula (AVF) arising from the costal marginal branch was also identified. This was not amenable to endovascular repair as two intervening branches, which fed normal cortex, could not be passed in order to isolate the fistula. He experienced a single generalized tonic-clonic seizure, lasting three minutes, approximately six hours after the embolization procedure. After two months of rehabilitation he was discharged with a Brunstrum stage $4 \mathrm{arm}, 5$ hand, $4 \mathrm{leg}$, and 3 foot. His language contained rare paraphasic errors and occassional word-finding pauses.

\section{Discussion}

This case represents the first report of an $\mathrm{ICH}$ from an underlying AVM being triggered by the ingestion of the sympathomimetic pseudoephedrine found in an over-the-counter decongestant medication. In routine drug surveillance programs

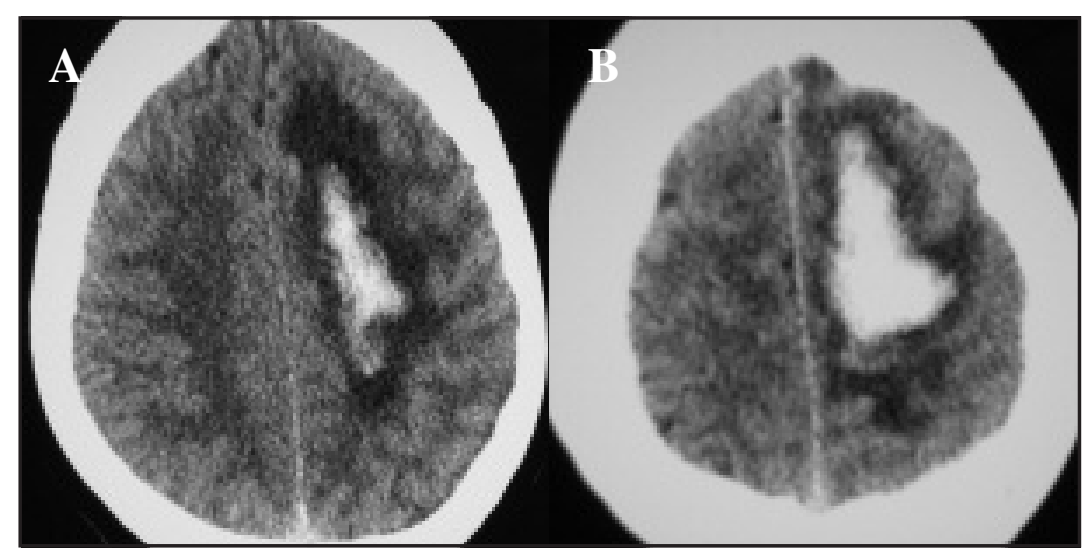

Figure 1: Non-contrast axial computerized tomography scans demonstrating a large ovalshaped left frontoparietal hemorrhage in the region of the centrum semiovale with surrounding vasogeic edema and limited mass effect. Panel A is a few millimeters above the superior margins of the lateral ventricles. Panel $B$ shows further extension into the high convexity region. 




Figure 2: Magnetic resonance imaging of the left frontoparietal centrum semiovale hematoma. Panel A is an axial T1 weighted image. Panel $B$ is an axial T2 weighted image. Panels $C$ and $D$ are parasaggital and coronal $T 1$ weighted images, respectively. Both $A$ and $B$ demonstrate the evolving peripheral methemoglobin in the early subacute phase. In panel $D$ there is a parafalcine location of the hematoma mass. Gadolinium contrast studies were performed but did not demonstrate significant enhancement.

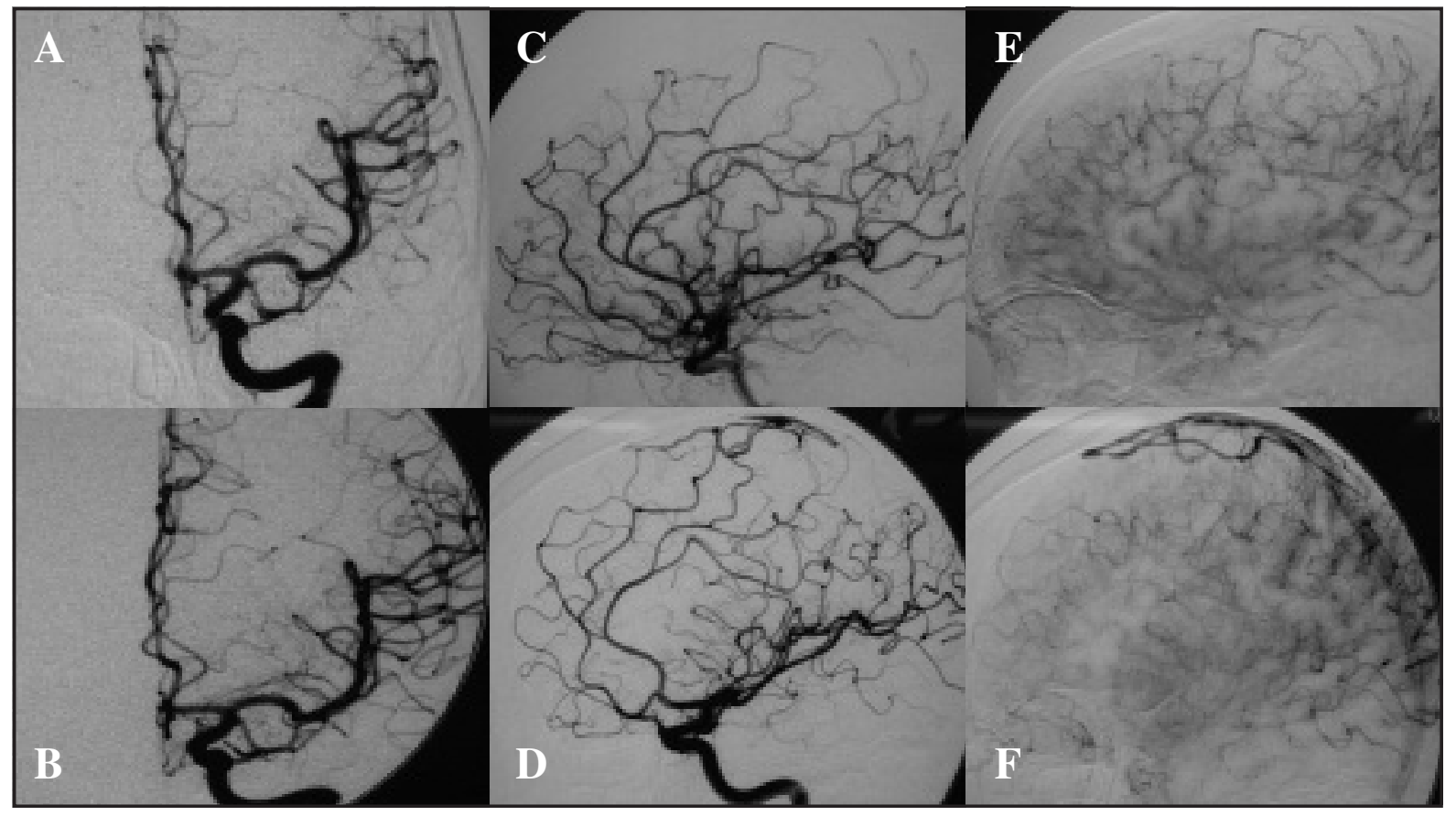

Figure 3: Selective left internal carotid cerebral angiograms taken in the acute (Panels $A, C, \& E$ ) and post-acute stages (Panels B, $D, \& F)$. Panel A demonstrates an arterial phase central hypovascularized region (*) due to the combined mass effects of hematoma and edema whereas Panel B reveals renormalization of the local blood flow after partial resolution of the hematoma. Panel $C$ provides no evidence of the arteriovenous malformation which only later became apparent (Panel D) at the convexity. Panel E demonstrates a normal capillary phase whereas Panel F shows early filling of the superior saggital sinus during the capillary phase. 
the US FDA categorizes an adverse event as definite if the symptoms developed within an interval that was consistent with the drug's expected peak plasma concentration. ${ }^{20}$ In the present case, the patient consumed $30 \mathrm{mg}$ of pseudoephedrine hydrochloride 1.5 hours prior to symptom onset. He had previously been taking this decongestant nightly for one year. The chronic usage pattern is important because the peak plasma concentration, which occurs approximately 0.5-2 hours postingestion, is expected to be quantitatively higher after multiple dosings compared to a single oral dose. ${ }^{22}$ Therefore, the ICH was temporally coupled to the known pharmacokinetics of pseudoephedrine.

The mechanism of sympathomimetic-induced $\mathrm{ICH}$ is not fully known. It is believed to arise from multifocal vasospasm which produces a picture of angiographic beading reminiscent of vasculitis. . $14,15,23,24$ These findings are nonspecific for cerebral arteritis and likely reflect segmental vasoconstriction rather than a drug-mediated immune vasculitis. ${ }^{11}$ It may be that the arteries within the AVM are vulnerable to exogenous vasoconstrictors increasing the bleeding diathesis. Arteriovenous malformations are known to release norepinephrine and renin predisposing to postsurgical hypertension. ${ }^{25}$ While systemic hypertension increases the bleeding risk for patients with atherosclerotic and hypertensive angiopathy its role in ephedra-related ICH is unclear. This is particularily so given that recommended dosages for pseudoephedrine failed to elicit significant excursions in blood pressure in humans. ${ }^{26}$ Therefore, unpredictable idiosyncratic responses probably complicate the pathogenesis.

The presence of an AVM confounds the issue of whether the pseudoephedrine played a primary etiologic role. Small arteries within AVMs exhibit deranged angioarchitecture with deficient lamina muscularis and possess abnormal rheology placing them at increased risk for hemorrhage. ${ }^{27}$ Additionally, the presence of a small AVF renders the source of the hemorrhage uncertain. Interestingly, microdissection of plexiform AVMs, revealed that many histologically discrete vessels within the nidus directly anastomose with the venous drainer implying a fundamental similarity between AVMs and AVFs. ${ }^{28}$ The absence of any demonstrable venous occlusion, which is thought to cause hemorrhage in AVFs, may permit speculation that the AVM was responsible.

Prevalence estimates predict that $0.01-0.5 \%$ of the population harbor latent AVMs with an annual risk of hemorrhage ranging from 1-4\%. ${ }^{29,30}$ The preponderance of cerebral AVMs present before the age of 40 years. Intracranial hemorrhage is the most common scenario with reports of disparate frequencies ranging from $30-82 \% .{ }^{31}$ Autopsy data suggests that $88 \%$ of AVMs are asymptomatic during life. ${ }^{32}$ However, modifying risk factors include (1) small size, (2) exclusively deep venous drainage, ${ }^{33}$ and (3) high intranidal pressure. ${ }^{34}$ Favourable factors for our patient were age (i.e., over 40 years) and superficial venous drainage. Intranidal pressures were not obtained. The small size likely represented the greatest intrinsic risk for bleeding.

Only one other case report has linked an ephedra alkaloid, phenylpropanolamine, to an ICH in a patient with an AVM. ${ }^{12}$ Indeed, AVMs rupture spontaneously. However, given the growing concern over the risk for sympathomimetic-induced cerebral hemorrhages in patients with normal cerebral vascular anatomy the case is even greater for those harboring intrinsic vascular anomalies such as an AVM. Caution is therefore recommended regarding ephedra alkaloid exposure in any patient who has had an incidental discovery of an AVM. Lastly, in a recent case series, only four of 22 patients with confirmed sympathomimetic-induced stroke (hemorrhagic in 21 patients) received follow-up angiographic studies. ${ }^{35}$ The diagnostic importance of follow-up cerebral angiography is highlighted by this case and should be considered in all patients with sympathomimetic-related ICH.

\section{REFERENCES}

1. Lake CR, Gallant S, Masson E, Miller P. Adverse drug effects attributed to phenylpropanolamine: a review of 142 case reports. Am J Med 1990; 89: 195-208.

2. Glick R, Hoying J, Cerullo L, Perlman S. Phenylpropanolamine: an over-the-counter drug causing central nervous system vasculitis and intracerebral hemorrhage. Case report and review. Neurosurgery 1987; 20: 969-974.

3. Kase CS, Foster TE, Reed JE, Spatz EL, Girgis GN. Intracerebral hemorrhage and phenylpropanolamine use. Neurology 1987; 37: 399-404.

4. Mueller SM, Muller J, Asdell SM. Cerebral hemorrhage associated with phenylpropanolamine in combination with caffeine. Stroke 1984; 15: 119-123.

5. Johnson DA, Etter HS, Reeves DM. Stroke and phenylpropanolamine use. Lancet 1983; 2: 970.

6. King J. Hypertension and cerebral haemorrhage after trimolets ingestion. Med J Aust 1979; 2: 258.

7. Kikta DG, Devereaux MW, Chandar K. Intracranial hemorrhages due to phenylpropanolamine. Stroke $1985 ; 16: 510-512$.

8. Fallis RJ, Fisher M. Cerebral vasculitis and hemorrhage associated with phenylpropanolamine. Neurology 1985; 35: 405-407.

9. McDowell JR, LeBlanc HJ. Phenylpropanolamine and cerebral hemorrhage. West J Med 1985; 142: 688-691.

10. Maher LM, Peterson PL, Dela-Cruz C. Postpartum intracranial hemorrhage and phenylpropanolamine use. Neurology 1987; 37: 1686

11. Stoessl AJ, Young GB, Feasby TE. Intracerebral haemorrhage and angiographic beading following ingestion of catecholaminergics. Stroke 1985; 16: 734-736.

12. Chung YT, Hung DZ, Hsu CP, Yang DY, Wu TC. Intracerebral hemorrhage in a young woman with arteriovenous malformation after taking diet control pills containing phenylpropanolamine: a case report. Zhonghua Yi Xue Za Zhi (Taipei) 1998; 61: 432-435.

13. Hamilton RS, Sharieff G. Phenylpropanolamine-associated intracranial hemorrhage in an infant. Am J Emerg Med 2000; 18 : 343-345.

14. Maertens P, Lum G, Williams JP, White J. Intracranial hemorrhage and cerebral angiopathic changes in a suicidal phenylpropanolamine poisoning. South Med J 1987; 80: 15841586.

15. Veyrac G, Huguenin H, Guillon B, et al. [Cerebral meningeal hemorrhage and acute cerebral angiopathy associated with the taking of phenylpropanolamine: a new case]. Therapie 2001; 56 : 323-327.

16. Kizer KW. Intracranial hemorrhage associated with overdose of decongestant containing phenylpropanolamine. Am J Emerg Med 1984; 2: 180-181.

17. Kernan WN, Viscoli CM, Brass LM, et al. Phenylpropanolamine and the risk of hemorrhagic stroke. N Engl J Med 2000; 343: 1826-1832.

18. Bruno A, Nolte KB, Chapin J. Stroke associated with ephedrine use. Neurology 1993; 43: 1313-1316.

19. Anonymous. Adverse events associated with ephedrine-containing products--Texas, December 1993-September 1995. MMWR Morb Mortal Wkly Rep 1996; 45: 689-693.

20. Haller CA, Benowitz NL. Adverse cardiovascular and central nervous system events associated with dietary supplements containing ephedra alkaloids. N Engl J Med 2000; 343: 1833-1838. 
21. Dowd J, Bailey D, Moussa K, et al. Ischemic colitis associated with pseudoephedrine: four cases. Am J Gastroenterol 1999; 94: 24302434.

22. Kanfer I, Dowse R, Vuma V. Pharmacokinetics of oral decongestants. Pharmacotherapy 1993; 13: 116S-128S.

23. Ryu SJ, Lin SK. Cerebral arteritis associated with oral use of phenylpropanolamine: report of a case. J Formos Med Assoc 1995; 94: 53-55.

24. Forman HP, Levin S, Stewart B, Patel M, Feinstein S. Cerebral vasculitis and hemorrhage in an adolescent taking diet pills containing phenylpropanolamine: case report and review of literature. Pediatrics 1989; 83: 737-741.

25. Bloomfield EL, Porembka DT, Ebrahim ZY, et al. Analysis of catecholamine and vasoactive peptide release in intracranial arterial venous malformations. J Neurosurg Anesthesiol 1996; 8: 101-110.

26. Drew CD, Knight GT, Hughes DT, Bush M. Comparison of the effects of D-(-)-ephedrine and L-(+)-pseudoephedrine on the cardiovascular and respiratory systems in man. $\mathrm{Br} \mathrm{J}$ Clin Pharmacol 1978; 6: 221-225.

27. Nataf F, Meder JF, Ghossoub M, Merienne L. [Hemorrhage in arteriovenous malformations: clinical and anatomic data]. Neurochirurgie 2001; 47: 158-167.
28. Tanaka R, Miyasaka Y, Fujii K, Kan S, Yagishita S. Vascular structure of arteriovenous malformations. J Clin Neurosci 2000; 7: $24-28$.

29. Fleetwood IG, Steinberg GK. Arteriovenous malformations. Lancet 2002; 359: 863-873.

30. Ondra SL, Troupp H, George ED, Schwab K. The natural history of symptomatic arteriovenous malformations of the brain: a 24-year follow-up assessment. J Neurosurg 1990; 73: 387-391.

31. Mast H, Mohr JP, Osipov A, et al. "Steal" is an unestablished mechanism for the clinical presentation of cerebral arteriovenous malformations. Stroke 1995; 26: 1215-1220.

32. McCormick WF. Classification, pathology, and natural history of angiomas of the central nervous system. Wkly Update Neurol Neurosurg 1978; 14: 2-7.

33. Kader A, Young WL, Pile-Spellman J, et al. The influence of hemodynamic and anatomic factors on hemorrhage from cerebral arteriovenous malformations. Neurosurgery 1994; 34: 801-807.

34. Marks MP, Lane B, Steinberg GK, Chang PJ. Hemorrhage in intracerebral arteriovenous malformations: angiographic determinants. Radiology 1990; 176: 807-813.

35. Cantu C, Arauz A, Murillo-Bonilla LM, Lopez M, Baringagarrementeria F. Stroke associated with sympathomimetics contained in overthe-counter cough and cold drugs. Stroke 2003 34: 1667-1673. 